\title{
PROPOSTA DE INTEGRAÇÃO DE VEÍCULO LEVE SOBRE TRILHOS AO SISTEMA DE TRANSPORTE PÚBLICO DE PASSAGEIROS DE CURITIBA
}

\author{
G. M. de O. Belich'; V. H. Bannach²; P. S. Monteiro ${ }^{3}$ \\ 1,2,3 Universidade Positivo, R. Professor Pedro Viriato Parigot de Souza, 5300, Campo Comprido, Curitiba/PR \\ gabrielbelich@gmail.com ${ }^{1}$,vhb_03@hotmail.com²,patricia.monteiro@prof.up.edu.br ${ }^{3}$
}

\begin{abstract}
Resumo: A proposta conceitual de integração do Veículo Leve Sobre Trilhos (VLT) ao Sistema de Transporte Público de Curitiba visa criar uma forma alternativa e sustentável para usuários da capital paranaense. Para isso, foi escolhida uma linha que atualmente está em estudo pelo Instituto de Pesquisa e Planejamento Urbano de Curitiba (IPPUC) para a implantação de um modal elétrico. Esta linha é a Conectora 3, que liga o Terminal Fazendinha a Estação Marechal Floriano Peixoto. Assim sendo, o traçado foi adaptado e compatibilizado com a infraestrutura já existente baseado nas larguras, inclinaçôes e raios das vias seguindo as normas de acessibilidade e especificaçôes da Associação Nacional de Transportes Públicos (ANTP) e Companhia Brasileira de Trens Urbanos (CBTU). Para a estimativa de demanda do novo modal proposto, foram realizados estudos em campo de Sobe-Desce e Frequência e Ocupação Visual (FOV) no intuito de verificar o maior movimento e gerar um perfil da linha em estudo para entáo realizar os dimensionamentos operacionais. Com a definiçáo do tempo de ciclo e da demanda, foi possível definir o modelo compatível do VLT, a frota e os horários de partida em cada ponto.
\end{abstract}

Palavras-chave: Modal elétrico, Transporte público, Veículo leve sobre trilhos, VLT.

Abstract: This conceptual proposal for integrating the Light Rail Vehicle (LRT) into Curitiba's Public Transportation System aims to create an alternative and sustainable way for users of Paranás capital. For this, a route previously designed by the Institute of Research and Urban Planning of Curitiba (IPPUC) was chosen for implementation feasibility analysis of an electric transportation technology. This route is Connector 3, which connects Fazendinha Station to Marechal Floriano Peixoto Station. Therefore, the layout was adapted based on local inclinations and paths widths that would allow the passage of a LRT, considering compatibilization with the existing infrastructure. To define operational parameters, demand-forecasting surveys were carried out. Based on these features, a compatible model of a LRT was chosen, and according to its specification, travel times, timetable and corresponding fleet were estimated.

Keywords: Electric transportation technology, Public transportation, Light rail vehicle, LRV, Demand forecast. 


\section{Introduçáo}

No panorama do Brasil no início do século XX, o país possuía uma complexa malha ferroviária para bondes elétricos e esse era o principal meio de locomoção dos centros urbanos. Após a crise de 1929, o número de migraçóes da população das lavouras para as cidades aumentou e os sistemas de bondes não conseguiram acompanhar a nova demanda, abrindo espaço para outros tipos de transporte, priorizando o uso privado [1]. Nesse cenário, em Curitiba - PR, os bondinhos são desativados e os ônibus passam a ser utilizados, e é desenvolvida, em 1955, sob gestão do governador do estado Ney Braga, a regulamentação do transporte coletivo e o Decreto 503/55 que permite a concessão das empresas para operação dos ônibus e as lotaçôes da cidade. Dez anos depois, no ano de 1965 na gestão do prefeito Ivo Arzua, foi criado o Instituto de Pesquisa e Planejamento Urbano de Curitiba (IPPUC). O propósito do IPPUC era elaborar, coordenar e monitorar o Plano Diretor da cidade que fundamentava um planejamento urbano de crescimento linear e de integração das estruturas físicas e funcionais da cidade sobre o tripé de Transporte Coletivo, Sistema Viário e Uso do solo, no intuito de direcionar o crescimento da capital PMC (2014). No ano de 1970, é introduzido o Bus Rapid Transit (BRT), que consiste, segundo [2], em um modo de transporte público sobre pneus veloz e flexível, combinando estaçóes, veículos, serviços, vias e elementos de Sistema Inteligente de Transporte (SIT) em um sistema integrado. Logo os anos se passaram e o sistema de ônibus urbano de Curitiba foi gradualmente melhorado, até alcançar o status de primeiro BRT completo do mundo [3].

Atualmente, de acordo com a empresa que gerencia e planeja a operação do transporte coletivo da capital, Urbanização de Curitiba S/A [4], a frota total de Curitiba é de 1280 ônibus distribuídos em 244 linhas convencionais e 4 estruturais para o transporte de maior volume de passageiros sendo eles: I - Eixo Norte-Sul; II - Eixo Oeste-Leste; III - Eixo Boqueirão e IV - Linha Verde. Cada tipo de linha obedece a uma função na rede integrada de transporte (RIT), permitindo ao usuário a utilização de mais de uma linha de ônibus com o pagamento de apenas uma tarifa. As integraçóes ocorrem nos terminais, onde o usuário pode desembarcar de uma linha e embarcar em qualquer outra dentro daquele espaço sem necessidade de nova tarifa.

Apesar de todo reconhecimento e avanço que a capital paranaense tem no âmbito do transporte coletivo, organização e planejamento urbano, já se passaram quase cinco décadas desde a implantação dos BRT’s e seu sistema de integração, sinalizando hoje, certa saturação [5]. Reconhecendo essas e outras vertentes, a prefeitura atualizou seu Plano Diretor no ano de 2014 com uma das propostas para alinhar o número de passageiros e incentivar o uso do transporte coletivo em Curitiba. A proposta seria a requalificação viária e inserção de um novo modal elétrico nos principais eixos que cortam a capital no sentido Oeste-Leste, chamados de conectores, por ligar a regiáo industrial da cidade aos eixos estruturais existentes complementando e apoiando os mesmos. São avaliadas hoje novas opçóes elétricas para compor a sua Rede Integrada de Transportes por apresentar menor ruído, ser menos poluente, ter boa aceitaçáo pelos usuários e ainda, segundo [6], por ser um modal de 
transporte público que possui certa facilidade de inserção na estrutura viária existente além de bom desempenho de serviço operacional e pelo menos 30 anos de vida útil.

Sendo assim, este trabalho visa desenvolver uma proposta de integração do Veículo Leve Sobre Trilhos (VLT) ao sistema público de transporte de passageiros vigente em Curitiba para a Linha Conectora 3, conforme indicada na Figura 1, por apresentar elevado crescimento populacional frente as outras conectoras, por estar na rota do centro geométrico da capital (Terminal Portão) [7].

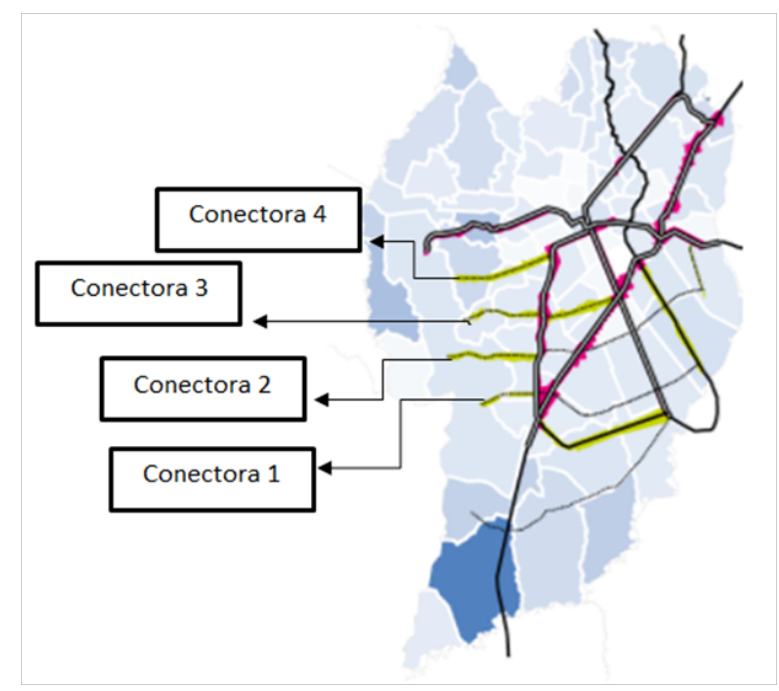

Figura 1 - Vias conectoras em Curitiba PR [8].

\section{Metodologia}

A primeira etapa incluiu a caracterização da situação atual do transporte público de passageiros em Curitiba: sua estrutura de funcionamento integrado, a frota utilizada, os modelos de veículos bem como suas capacidades e linhas operantes com base nos dados disponibilizados pela URBS. Para isso, e esclarecimentos acerca do planejamento e crescimento urbano de Curitiba, alinhado com o plano diretor e suas diretrizes para os próximos anos, bem como os estudos sobre os eixos conectores da capital, foi realizada uma reuniáo com o engenheiro civil do setor de mobilidade urbana do IPPUC, José Álvaro Twardowski. Com base nestas discussões, foi definida a Conectora 3 (Fazendinha-Portão-Marechal) para o desenvolvimento deste projeto.

\subsection{Características de infraestrutura e traçado}

O traçado da linha para a inserção do VLT foi elaborado baseado nas áreas de atendimento da Conectora 3 e seus principais pontos de referência a serem ligados, esquematizados na Figura 2. Nessa fase foram utilizadas ferramentas como o mapa de arruamento digital da capital e imagens de satélite do Google Maps, além de idas a campo para melhor acompanhamento visual. O referencial 
teórico adotado para a pré-seleção das vias se baseou nas dimensôes (largura, comprimento, raios e inclinaçôes) e normas da ANPT e NBR 9050:2015 [9]. Nesse estágio de conhecimento e análise das vias, apenas as que tiveram largura maior ou igual a 6,50 metros foram cogitadas a receber a infraestrutura do VLT.

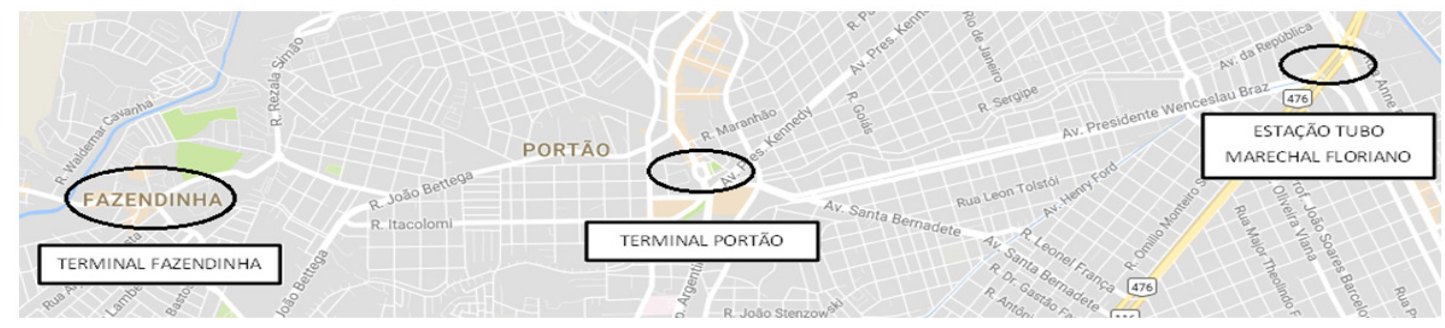

Figura 2 - Pontos de referências a serem conectados.

\subsubsection{Larguras e comprimentos}

Para a análise e predefinição das vias a serem escolhidas para a infraestrutura do modal, foram consideradas vias duplas de VLT para todo traçado, ou seja, foram necessárias que todas elas possuíssem pelo menos 6,50 metros de largura e passeios de pelo menos 2,40 metros sendo 1,20 metros para cada lado. Esse método levou em conta a pior condição da via: trecho sem estação de parada e sem tráfego misto de veículos no intuito de verificar a necessidade de vias distintas para sua infraestrutura. Foram definidas as vias aptas a receberem o modal quanto a largura e para representar isso, posteriormente realizadas em AutoCAD as principais seçóes, respeitando as dimensóes normativas e indicando as possíveis requalificaçôes viárias necessárias.

\subsubsection{Raios}

Os raios de curvas foram medidos através do mapa digital de arruamento de Curitiba, verificado se atende aos 20 metros de raio necessários à viabilidade técnica de implantação do VLT, como demonstra a Figura 3. 


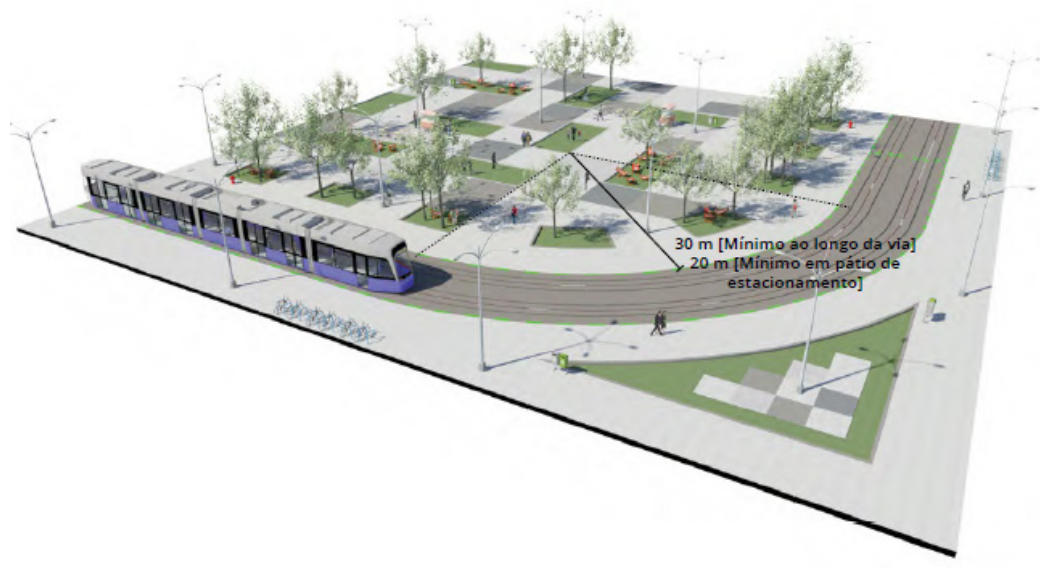

Figura 3 - Raio mínimo de curvatura para VLT’s [10].

\subsubsection{Declividades}

Após a verificação do porte das vias, foi realizada a verificação da altimetria e declividades máximas. Utilizando o mapa de curvas de nível, foram calculadas as inclinaçôes a cada intervalo máximo de 150 metros de distância no intuito de respeitar a declividade máxima de 7\% suportada pelo VLT. Quando presentes curvas ou um grande desnível em um intervalo menor que 150 metros, as distâncias entre estacas foram reduzidas para o cálculo da inclinação.

\subsection{Dados de demanda}

A partir do traçado definido e dos estudos preliminares de demanda das linhas de ônibus operantes entre os terminais Fazendinha e Portão (ambos presentes na Conectora 3) disponibilizados pela URBS, foram analisados trechos das linhas Interbairros V e Circular Sul para a estimativa de usuários do VLT em um dia útil por atenderem a regiáo de interesse. Os dados de demanda disponíveis referiam-se aos itinerários totais das linhas mencionadas; para uma melhor aproximação das reais condiçóes operacionais, foram realizadas (também nessas linhas, mas nos trechos de interesse) pesquisas de campo do tipo Sobe-Desce e Frequência e Ocupação Visual (FOV) para estimativa de demanda. A Figura 4 indica os trechos de interesse das linhas Interbairros V e Circular Sul. 


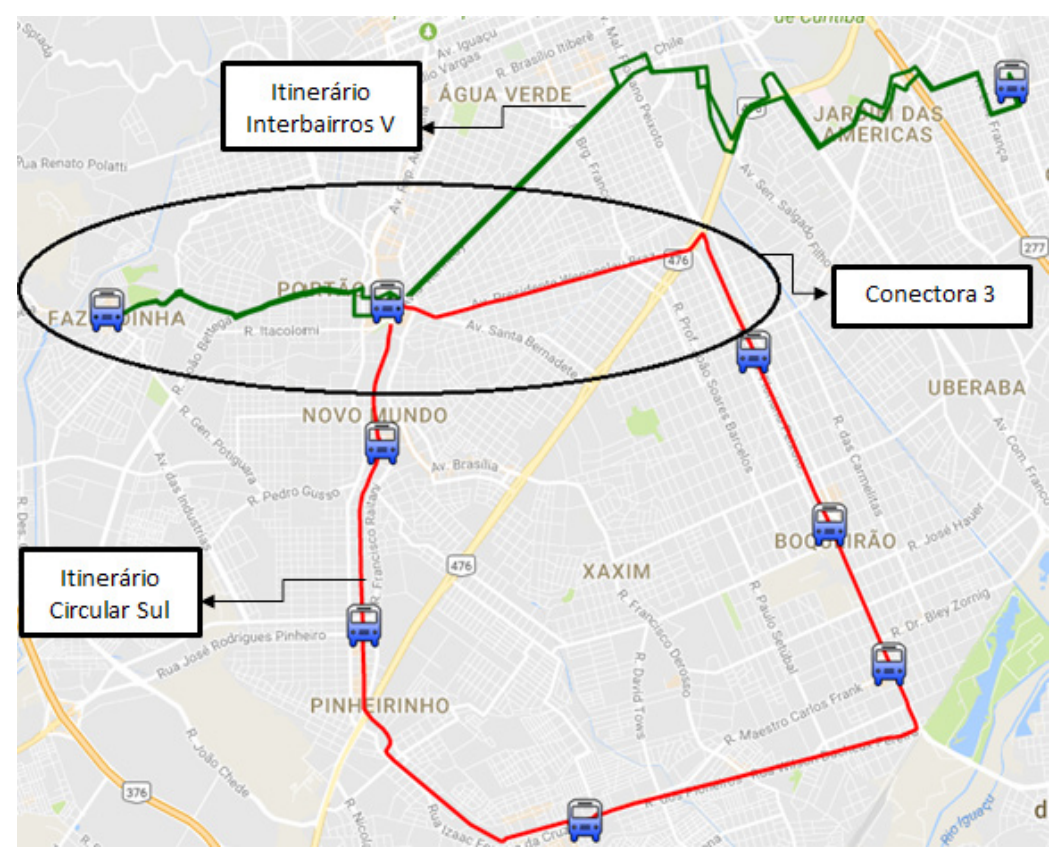

Figura 4 - Linhas Interbairros V e Circular Sul e segmento Conectora 3

\subsubsection{Pesquisa Sobe-Desce}

Visando identificar o ponto de maior movimento das linhas Interbairros V e Circular sul, foi feita a contagem do número de usuários que realizaram o embarque e o desembarque em cada ponto de parada. A pesquisa foi realizada no dia 25 de agosto de 2017 no período da manhã. Ao identificar o ponto de maior movimento no trajeto percorrido, realizou-se, neste local, pesquisa de Frequência e Observação Visual para estabelecimento de previsão de demanda.

\subsubsection{Pesquisa de Frequência e Ocupação Visual (FOV)}

No ponto admitido com maior movimento, na interseção com a rua Arthur Mohr foi realizada a pesquisa de Frequência e Ocupação Visual (FOV). Esta pesquisa visou classificar o nível de ocupação dos ônibus durante todo o horário de funcionamento das linhas Interbairros V e PUC-Fazendinha. Os níveis de ocupação foram classificados em 6 faixas sendo o nível 0 para 0 passageiros a bordo e o nível 5 para 140 passageiros a bordo, de acordo com a capacidade máxima prevista pela URBS para modelos de ônibus articulados. A pesquisa foi realizada no dia 29 de agosto de 2017 das 06:00 horas da manhã até as 22:45 horas.

Os dados coletados foram dispostos em intervalos de uma hora de maneira a ser obtido o número de passageiros por hora por sentido e assim, traçado o perfil de demanda da linha em estudo durante um dia útil. 


\subsection{Características operacionais do VLT}

O cálculo para a obtenção das características operacionais foi definido após a escolha do modelo de VLT Citadis da marca Alstom por possuir fabricação brasileira, capacidade modular, ser bidirecional (cabine nas duas extremidades) e atender as normas técnicas da CBTU. A máxima aceleração e máxima frenagem foram adotadas conforme as especificaçóes do modelo sendo neste caso, 1,3 m/ $\mathrm{s}^{2}$ e $1,2 \mathrm{~m} / \mathrm{s}^{2}$, respectivamente.

\subsubsection{Distância das estações}

Utilizando novamente o mapa de arruamento da capital em conjunto com as recomendaçóes de distanciamento de [11], além das idas a campo para a verificação do porte dos passeios, vias e suas possíveis potencialidades em acordo com a norma ABNT NBR 9050:2015 para o recebimento das estaçôes em nível, foram definidos os pontos de parada do VLT.

\subsubsection{Tempo de ciclo}

A partir da definição do modelo do VLT, bem como suas respectivas especificaçóes, foi calculado o tempo e a distância de aceleração e frenagem, tempo e distância percorrida na velocidade de cruzeiro e tempo e distância de parada para cada estação, obtendo-se assim, pela soma dos tempos entre pontos de parada, o tempo de ciclo do VLT.

\section{Resultados}

O traçado final do VLT para inserção no segmento Conectora 3 totaliza 7,625 km de extensão ligando os terminais Fazendinha, Portão e Estação Tubo Marechal Floriano Peixoto O itinerário do modal sobre trilhos foi proposto para as seguintes vias nos dois sentidos: Rua Carlos Klemtz, Rua Itatiaia, Avenida Presidente Kennedy, Rua Wilson de França, Avenida Santa Bernadete, Avenida Presidente Wenceslau Braz e BR-476. As paradas ao longo do itinerário foram distanciadas entre si de modo a atender as normas previstas para o bom funcionamento do modal e ainda, em locais onde a implantaçáo das estaçóes em nível tivesse espaço necessário sem a necessidade de grandes requalificaçôes viárias. O trecho situado nas ruas Carlos Klemtz e Itatiaia foi proposto considerando via compartilhada entre o VLT (mão dupla) e veículos de uso privado (mão única). Na avaliação do eixo de projeto, a curvatura crítica está localizada na rotatória da Rua Carlos Klemtz, com 60,4 metros, superior aos 20 metros mínimos.

$\mathrm{Na}$ avaliação da altimetria viária, foram detectadas inclinaçôes de 11,43\% e 10,39\%, as quais não atendem a tolerância (a inclinação máxima permitida é de 7\% em distâncias de 150 metros para o funcionamento do VLT). No entanto, para o funcionamento do sistema e por estar localizada na 
Avenida Presidente Wenceslau Braz e a mesma possuir um largo canteiro plano na região central da rua (ao lado da região crítica), a solução adotada para que o VLT inclui leve desvio do modal para esse canteiro nesse trecho. A Figura 5 mostra o perfil altimétrico do traçado com seu trecho crítico destacado em vermelho.

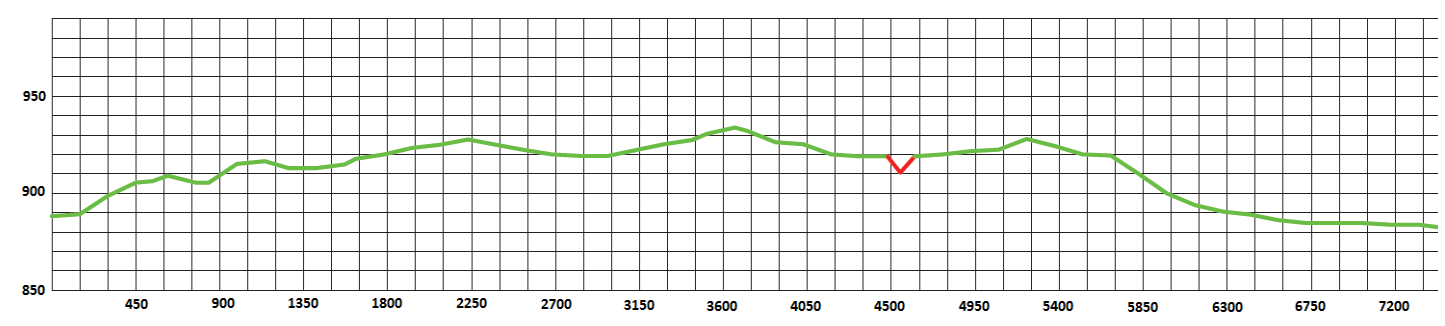

Figura 5 - Perfil altimétrico do traçado proposto.

As pesquisas de sobe-desce e FOV (frequência e observação visual) possibilitaram a estimativa do perfil da demanda, apresentado na Figura 6 a partir da qual se estabeleceu o dimensionamento operacional do modal.

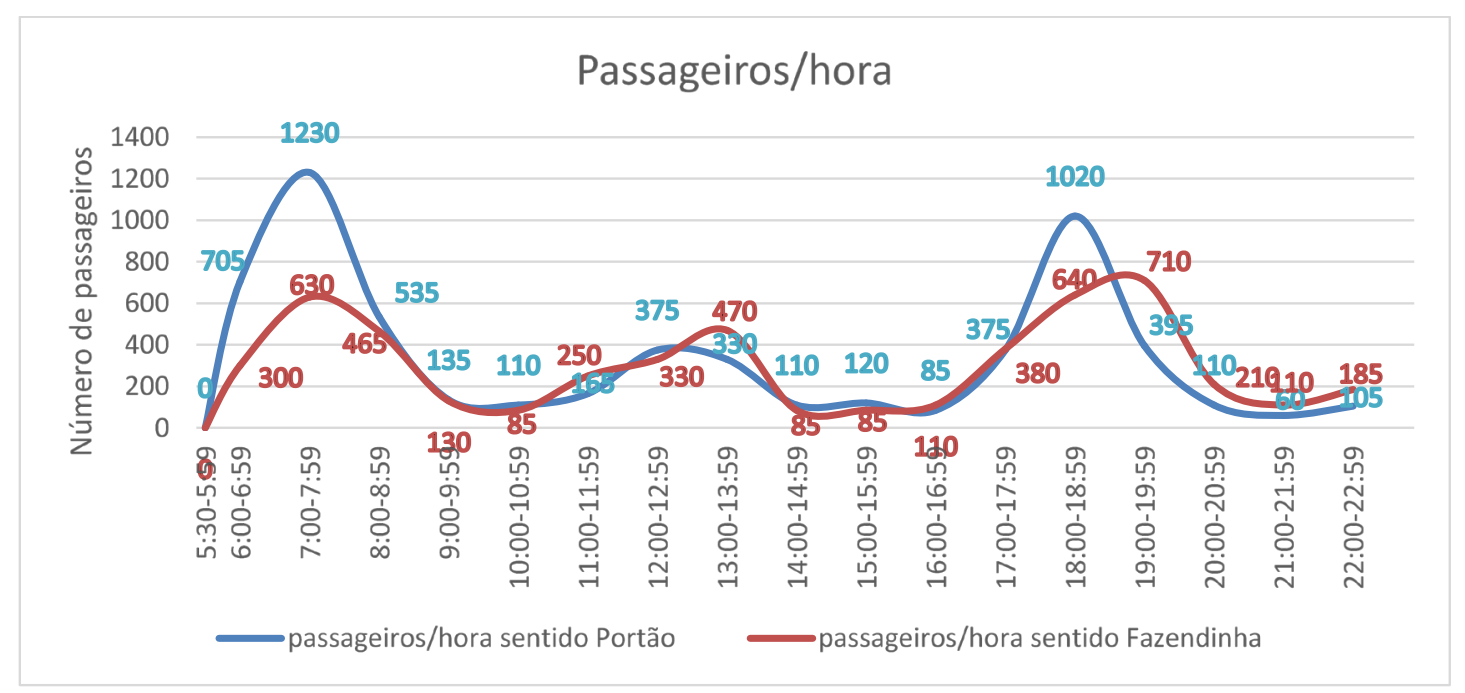

Figura 6 - Perfil de passageiros por hora no ponto de maior movimento.

O tempo de ciclo tomou como base as características técnicas do veículo Citadis da marca Alstom sendo sua capacidade, comprimento, largura, aceleração e frenagem dispostos na Tabela 1 resumida a partir do catálogo da marca. 
Tabela 1 - Configuraçóes dos veículos Citadis da Alstom.

\begin{tabular}{ccccc}
\hline Comprimento $(\mathbf{m})$ & Largura $(\mathbf{m})$ & Capacidade (passageiros) & Aceleraçáo $\left(\mathbf{m} / \mathbf{s}^{2}\right)$ & Frenagem $\left(\mathbf{m} / \mathbf{s}^{2}\right)$ \\
\hline 32,20 & 2,40 & 200 & 1,30 & 1,20 \\
\hline
\end{tabular}

Da demanda estimada, foi estabelecida a oferta; tomando como base a capacidade dos veículos, foi definido o número de viagens por hora, o que permitiu a definição dos tempos de ciclo para cada situação. Dessas condições, associadas à extensão do traçado, de 7,625 km (15,250 km, nos dois sentidos), estima-se a velocidade média dos VLTs (compatíveis com as condiçóes de aceleração e frenagem, função da presença das estaçóes, bem como sua velocidade cruzeiro, admitida como 25 $\mathrm{km} / \mathrm{h}$ ). Estes dados encontram-se resumidos na Tabela 2.

Tabela 2 - Resumo tempo de ciclo VLT'S.

\begin{tabular}{ccc}
\hline VLTs por hora & Tempo de Ciclo & Velocidade média $(\mathbf{k m} / \mathbf{h})$ \\
\hline 5 & $00: 47: 01$ & 19,46 \\
6 & $01: 00: 14$ & 15,19 \\
7 & $01: 02: 15$ & 14,70 \\
\hline
\end{tabular}

\section{Conclusóes}

Tendo em vista os aspectos abordados na proposta de integração do VLT ao sistema de transporte público de Curitiba na Conectora 3, como as questôes de infraestrutura do traçado e condiçóes de operação do sistema desde a velocidade, capacidade, frequência e tempo de ciclo do modal, até a definição do fabricante e das possíveis integraçôes com o sistema existente, pôde-se considerar vantagens e desvantagens.

Nas questôes de infraestrutura, onde foram analisadas o porte das vias, suas capacidades, declividades máximas e ainda os raios de curva obedecendo as normas de acessibilidade, plano Diretor e condições técnicas da Associação Nacional de Transportes Públicos, ocorreram pontos críticos que podem ser considerados chaves na proposta. Enquanto a verificação dos raios de curva passaram nas verificaçôes sem maiores adaptaçôes, a declividade passou da máxima permitida (7\%) em um dos pontos do traçado que aproveitariam a infraestrutura existente. Porém, para viabilidade do sistema, pode ser proposto um desvio e novas requalificaçóes como soluçáo do problema.

Para o funcionamento operacional do sistema, foi definido o VLT modelo Citadis da marca Alstom por possuir fábrica localizada em Taubaté - São Paulo e pelo modelo ser o mesmo utilizado no Rio de Janeiro. Com as especificaçôes técnicas definidas a partir do modelo escolhido e ainda, com os dados de campo realizados na pesquisa Sobe-Desce e FOV para a determinação do comportamento da demanda de usuários que se deslocam pela conectora, foi possível dimensionar a frota de 5 veículos circulando e 1 veículo reserva, as condiçóes de operação e ainda, pontos de superdi- 
mensionamento devido a variação do comportamento de demanda em horários alternativos com tempo de espera atrativo para os usuários, resultando em uma possível desvantagem na decisão final da implantação do modal.

Nesse cenário, apesar do superdimensionamento inicial em algumas horas do dia, o novo sistema além de conectar-se aos principais eixos existentes da capital, poderia induzir os usuários da região a optar pelo novo modelo de transporte principalmente pelo conforto e pelo fácil acesso em superfície.

\section{Agradecimentos}

Somos gratos ao engenheiro José Álvaro Twardowski e equipe do IPPUC, pela presteza e disposição de atendimento.

\section{Referências}

[1] CARVALHO, L. "Governo Juscelino Kubitschek"; Brasil Escola, 2014. Disponível em <http://brasilescola.uol.com. br/historiab/juscelino-kubitschek.htm>. Acesso em: 23 mar. 2017.

[2] LEVINSON, H.; ZIMMERMAN, S.; CLINGER, J.; GAST, J.; RUTHERFORD, S.; BRUHN, E.; Bus Rapid Transit Volume 2: Implementation Guidelines. Transit Cooperative Research Program: Report 90, Washington, DC, USA, 2003.

[3] LINDAU, L.A.; HIDALGO, D.; FACCHINI, D. Curitiba, the Cradle of Bus Rapid Transit. Built Environment - Volume: 36 I Issue: 3 I Pages: 274-282, 2010.

[4] URBS S/A. Urbanização de Curitiba S/A. Disponível em: <https://www.urbs.curitiba.pr.gov.br/transporte/redeintegrada-de-transporte> Acesso em: 29 maio 2017.

[5] ULBRICH, G. O que mudou nas cidades brasileiras que implantaram o VLT? | Futuro das Cidades | Gazeta do Povo. Disponível em: <http://www.gazetadopovo.com.br/vida-e-cidadania/futuro-das-cidades/o-que-mudou-nascidades-brasileiras-que-implantaram-o-vlt-f3baauxpudqeafgfdrsysopfw>. Acesso em: 13 abr. 2017.

[6] BERNARDES, F. F.; MESQUITA, A. P.; Veículos Leves Sobre Trilhos no Brasil: Análise Metodológica e Estudo de Caso - Fortaleza e Rio de Janeiro. Dissertação de Mestrado, Universidade Federal de Uberlândia (UFU) - Instituto de Geografia. Uberlândia, 2014.

[7] IPPUC. Primeiro plano diretor de Curitiba é da década de 1960 - Prefeitura de Curitiba. Disponível em: $<$ http://www.curitiba.pr.gov.br/noticias/primeiro-plano-diretor-de-curitiba-e-da-decada-de-1960/32276>. Acesso em: 26 mar. 2017.

[8] AGÊNCIA DE NOTÍCIAS DA PREFEITURA DE CURITIBA. Destaques do Plano Diretor 2015 - Prefeitura de Curitiba. Disponível em: <http://www.curitiba.pr.gov.br/noticias/destaques-do-plano-diretor-2015/38591>. Acesso em: 6 jun. 2017.

[9] ABNT NBR 9050/2015: Acessibilidade a edificaçóes, mobiliário, espaços e equipamentos urbanos.

[10] ANPT - ASSOCIAÇÃO NACIONAL DOS TRANSPORTADORES DE PASSAGEIROS SOBRE TRILHOS; MINISTÉRIO DAS CIDADES; SECRETARIA NACIONAL DE MOBILIDADE URBANA; WRI BRASIL.

Caderno Técnico para Projetos de Mobilidade Urbana: Veículo Leve sobre Trilhos. Rio de Janeiro, 2016

[11] LERNER, Jaime. Avaliaçáo Comparativa das Modalidades de transporte Público Urbano. Solicitação da Associação Nacional das Empresas de Transportes Urbanos (NTU), Curitiba, PR. Julho de 2009. 